\title{
The effect of spironolactone in patients with resistant arterial hypertension in relation to baseline blood pressure and secondary causes of hypertension
}

\author{
Jan Vaclavik ${ }^{\mathrm{a}}$, Richard Sedlak ${ }^{\mathrm{b}}$, Jiri Jarkovskyc, Eva Kocianovaa ${ }^{\mathrm{a}}$, Milos Taborsky ${ }^{\mathrm{a}}$
}

\begin{abstract}
Aims. There are currently limited data about whether the effect of spironolactone in patients with resistant arterial hypertension depends on baseline blood pressure and the presence of a secondary cause of hypertension.

Methods. Patients with office systolic blood pressure (BP) $>140 \mathrm{mmHg}$ or diastolic BP $>90 \mathrm{mmHg}$, despite treatment with at least 3 antihypertensive drugs including a diuretic, were randomly assigned to receive spironolactone or a placebo for 8 weeks in a double-blind, placebo-controlled, multicentre trial (ASPIRANT).

Results. Analyses were done with 55 patients treated with spironolactone. The degree of BP reduction after 8 weeks of spironolactone treatment did not differ significantly between the three tertiles of baseline systolic BP and patients with and without a secondary cause of hypertension. The reduction of office systolic, office diastolic BP and office pulse pressure was significantly lower in the highest tertile with baseline diastolic BP $>97 \mathrm{mmHg}$.

Conclusions. Spironolactone treatment is effective to a similar extent both in patients with and without a secondary cause of hypertension and regardless of the baseline value of systolic BP. Less effect of spironolactone was found in patients with the highest baseline diastolic BP.
\end{abstract}

Key words: resistant hypertension, spironolactone, clinical trials, blood pressure, secondary hypertension

Received: February 10, 2012; Accepted with revision: July 19, 2012; Available online: October 31, 2012 http://dx.doi.org/10.5507/bp.2012.078

${ }^{a}$ Department of Internal Medicine I - Cardiology, University Hospital Olomouc and Faculty of Medicine and Dentistry, Palacky University Olomouc, Czech Republic

${ }^{b}$ Department of Internal Medicine, Prostejov Hospital, Prostejov

'Institute of Biostatistics and Analyses, Faculty of Medicine and Faculty of Science, Masaryk University, Brno

Corresponding author: Milos Taborsky, e-mail: milos.taborsky@seznam.cz

\section{INTRODUCTION}

Resistant hypertension is a common clinical problem faced by both primary care clinicians and specialists worldwide. It is defined as blood pressure (BP) that remains above goal in spite of the concurrent use of 3 antihypertensive agents of different classes prescribed at optimal dosages; one of the 3 agents used should be a diuretic ${ }^{1}$.

The prevalence of resistant hypertension is estimated, from large clinical trials, to be at least $10-15 \%$ of all hypertensive patients ${ }^{2,3}$. In a recently published analysis of the NHANES Survey (National Health and Nutrition Examination Survey) the prevalence of resistant hypertension was $12.8 \%$ in patients treated with antihypertensive drugs and $8.9 \%$ in all adult patients with hypertension ${ }^{4}$. If no secondary cause of hypertension is found, the use of multidrug treatment regimens including 3, 4 or more antihypertensive drugs, is usually necessary to lower blood pressure and thus prevent future cardiovascular events ${ }^{5}$.

Spironolactone is a mineralocorticoid receptor antagonist which was shown to lower blood pressure effectively in both general hypertensive patients and patients with primary aldosteronism ${ }^{6-8}$. A number of uncontrolled trials showed the positive effect of small doses of spironolactone in lowering blood pressure in patients with resistant arterial hypertension ${ }^{9-19}$. Spironolactone was usually administered in a daily dose of $25-50 \mathrm{mg}$ and its effect was usually assessed after 3-6 months. The addition of spironolactone to other antihypertensive medications usually led to a marked decrease of systolic BP (-14 to $-36 \mathrm{mmHg})$ and diastolic BP (-7 to $-12.5 \mathrm{mmHg})\left(\right.$ ref. $\left.^{20}\right)$. A recent randomized, double-blind, placebo-controlled, multicentre trial (ASPIRANT) found a significant decrease of systolic, but not diastolic BP, with the addition of $25 \mathrm{mg}$ of spironolactone compared to a placebo in patients with resistant hypertension ${ }^{21}$.

Currently, it is not completely clear how to identify patients for which treatment with spironolactone would be most effective. There is only limited data on whether the effect of spironolactone treatment in patients with resistant arterial hypertension depends on baseline blood pressure and differs depending on the presence or absence of a secondary cause of hypertension. For this reason, we decided to perform a post-hoc analysis of the data from the randomized ASPIRANT trial ${ }^{21}$.

\section{METHODS}

ASPIRANT was an investigator-led, prospective, multicentre, randomized, double-blind, placebo-controlled, parallel-group trial. The design and main results of the trial have been described previously ${ }^{21,22}$. We enrolled patients aged 18 years and above with resistant arterial hypertension, defined as office systolic BP >140 or diastolic 
BP >90 mmHg despite being treated with at least three antihypertensive drugs, including a diuretic. Patients with diabetes or chronic kidney disease (defined as serum creatinine $>133 \mu \mathrm{mol} / \mathrm{L}$ or proteinuria $>300 \mathrm{mg} /$ day) were enrolled if the office BP was $>130 / 80 \mathrm{mmHg}$.

The study was done in accordance with the principles of the Helsinki declaration. The study protocol was approved by ethics review and by the State Institute for Drug Control of the Czech Republic. Written informed consent was obtained from all patients prior to enrolment. This study was registered at clinicaltrials.gov as NCT00524615.

For safety reasons, we excluded all patients with severe hypertension (systolic BP $>180$ or diastolic BP $>110 \mathrm{mmHg}$ ) who needed an immediate adjustment of treatment, those with renal insufficiency with serum creatinine $>180 \mu \mathrm{mol} / \mathrm{L}$ or glomerular filtration rate $<40 \mathrm{~mL} /$ min calculated by the MDRD formula, hyperkalemia $>5.4 \mathrm{mmol} / \mathrm{L}$, hyponatremia $<130 \mathrm{mmol} / \mathrm{L}$, porphyria, pregnant or lactating women or women of fertile age not using effective contraception, patients with known prior hypersensitivity to the drug Verospiron ${ }^{\circledR}$ (spironolactone; Richter Gedeon Ltd., Czech Republic) or currently using any aldosterone antagonist (spironolactone, eplerenone or canreonate).

Patients were randomly assigned in a one-to-one ratio to receive either spironolactone at a dose of $25 \mathrm{mg}$ once daily or a placebo once daily in the morning, as an addon to their current antihypertensive therapy, in a blinded manner. After randomization, patients were followed for 8 weeks. Office blood pressure was recorded by a calibrated mercury sphygmomanometer in seated patients with their arm supported. The value was recorded as the average of the $2^{\text {nd }}$ and $3^{\text {rd }}$ measurements with a minimum delay of 3 minutes between the measurements. At baseline and 8 weeks, 24-h ambulatory blood pressure monitoring (ABPM) was performed using validated devices ${ }^{23,24}$. Average day-time blood pressure was calculated from values measured between 09:00 and 21:00, average night-time blood pressure from values measured between 01:00 and 06:00 and average $24 \mathrm{~h}$ blood pressure was calculated from all the values recorded by ABPM $\left(\right.$ ref. $\left.^{25}\right)$.

Serum sodium, potassium, chlorides, urea and creatinine, plasma renin activity (PRA), plasma aldosterone and aldosterone/renin ratio (ARR), microalbuminuria and proteinuria in a $24 \mathrm{~h}$ urine sample were measured at baseline and at 8 weeks. Free plasma metanephrines, serum TSH and urinary free and total cortisol in a $24 \mathrm{~h}$ urine sample were measured on baseline. Patients with a known secondary cause of hypertension were not enrolled into the trial, but the exclusion of secondary hypertension was not required by the study protocol prior to enrollment. Patients did not change the dosage or quantity of their antihypertensive medication throughout the trial.

After trial completion, patients were followed up clinically until December $1^{\text {st }}$, 2011. To perform this analysis, patients were stratified by baseline systolic and diastolic blood pressure, and the presence or absence of a secondary cause of hypertension found during the follow-up after study completion.
Standard descriptive statistics were applied in the analysis. Continuous variables were described using mean and standard deviation when the prerequisite of normality was fulfilled, and the median and $5^{\text {th }}$ and $95^{\text {th }}$ percentile range in case of non-normal distribution. Categorical variables were described by the number of cases and the percentages of categories. The statistical significance of differences among groups was analysed using the Mann Whitney $\mathrm{U}$ test and the Kruskal Wallis test. Statistical analysis was computed using SPSS 19.0.1 (IBM Corporation, New York, U.S.A.).

\section{RESULTS}

A total of 117 patients were enrolled in the trial from September 2007 to June 2010, with follow-ups during the next 2 months. The trial profile has already been published $^{21}$. Of the 59 patients enrolled into the spironolactone arm, 4 patients discontinued treatment prematurely ( 2 due to adverse events and 2 due to protocol violation). Analyses were done on 55 patients who were treated with spironolactone and finished the trial.

Baseline characteristics of the patients are shown in Table 1 . The mean patient age was approximately 61 years, the mean office BP was $155 / 93 \mathrm{mmHg}$ and the mean $24 \mathrm{~h}$ ABPM blood pressure 143/81 $\mathrm{mmHg}$. Isolated systolic hypertension (office systolic BP >140 $\mathrm{mmHg}$ and diastolic BP $<90 \mathrm{mmHg}$ ) was present in $36.4 \%$ of patients. Patients were using a mean of 4.6 antihypertensive drugs. All patients used diuretics, mostly hydrochlorothiazide or indapamide.

To evaluate the BP response to spironolactone treatment, patients were divided into tertiles according to baseline systolic and diastolic BP (Tables 2 and 3). The degree of $\mathrm{BP}$ reduction after spironolactone treatment did not differ significantly between the three tertiles of baseline systolic BP (Table 2). However, the reduction of office systolic, office diastolic BP and office pulse pressure was significantly lower in the highest tertile with a baseline diastolic BP > $97 \mathrm{mmHg}$ (Table 3).

After trial completion, patients were clinically followed up for a further 16 to 49 months (median 28 months). In 13 patients (24\%), a secondary cause of hypertension was found during subsequent evaluation within 6 months after completion of the trial. Most common was primary aldosteronism ( 8 patients), followed by renovascular hypertension (3), obstructive sleep apnoea (1) and nephrogenic hypertension (1). Patients with and without a secondary cause of hypertension had comparable BP reductions with spironolactone treatment (Table 4).

\section{DISCUSSION}

This subanalysis of a randomized trial showed that the addition of spironolactone in patients with resistant arterial hypertension using a mean of 4.6 antihypertensive drugs, led to a similar reduction in BP regardless of the presence or absence of a secondary cause of hypertension. 
Table 1. Patient demographics and baseline characteristics.

\begin{tabular}{|c|c|}
\hline Patient characteristics & Spironolactone group $(n=55)$ \\
\hline \multicolumn{2}{|l|}{ Demographic characteristics } \\
\hline Age (years) & $61.4( \pm 9.6)$ \\
\hline Sex (female) & $18(32.7 \%)$ \\
\hline Height $(\mathrm{cm})$ & $173.1( \pm 8.9)$ \\
\hline Weight $(\mathrm{kg})$ & $96.9( \pm 17.1)$ \\
\hline BMI $\left(\mathrm{kg} / \mathrm{m}^{2}\right)$ & $32.3( \pm 5.1)$ \\
\hline Heart rate $(\mathrm{bpm})$ & $67.8( \pm 10.4)$ \\
\hline \multicolumn{2}{|l|}{ Mean baseline blood pressure } \\
\hline Office BP (mmHg) & $154.9( \pm 10.4) / 92.6( \pm 10.7)$ \\
\hline ABPM day-time $\mathrm{BP}(\mathrm{mmHg})$ & $144.7( \pm 14.8) / 83.6( \pm 11.1)$ \\
\hline ABPM night-time $\mathrm{BP}(\mathrm{mmHg})$ & $136.4( \pm 19.0) / 76.7( \pm 13.4)$ \\
\hline 24-h ABPM BP (mmHg) & $143.1( \pm 13.5) / 81.1( \pm 10.2)$ \\
\hline \multicolumn{2}{|l|}{ Baseline serum laboratory characteristics } \\
\hline $\mathrm{Na}(\mathrm{mmol} / \mathrm{L})$ & $140.4( \pm 2.8)$ \\
\hline $\mathrm{K}(\mathrm{mmol} / \mathrm{L})$ & $4.2( \pm 0.5)$ \\
\hline $\mathrm{Cl}(\mathrm{mmol} / \mathrm{L})$ & $104.0( \pm 3.8)$ \\
\hline Urea $(\mathrm{mmol} / \mathrm{L})$ & $6.2(3.8 ; 10.4)$ \\
\hline Creatinine $(\mu \mathrm{mol} / \mathrm{L})$ & $81.0(56.0 ; 128.0)$ \\
\hline Glycemia (mmol/L) & $6.0(4.6 ; 17.3)$ \\
\hline Plasma renin activity $(\mathrm{ng} / \mathrm{mL} / \mathrm{h})$ & $0.4(0.1 ; 5.8)$ \\
\hline Aldosterone (ng/L) & $94(23 ; 297)$ \\
\hline Aldosterone/renin ratio ${ }^{\dagger}$ & $15.2(1.6 ; 235.0)$ \\
\hline \multicolumn{2}{|l|}{ Medication at randomization } \\
\hline Angiotensin-converting enzyme inhibitor & $42(76.4 \%)$ \\
\hline$\beta$ blocker & $41(74.5 \%)$ \\
\hline Calcium channel blocker & $49(89.1 \%)$ \\
\hline Diuretics & $55(100.0 \%)$ \\
\hline Angiotensin II receptor blocker & $25(45.5 \%)$ \\
\hline a blocker & $8(14.5 \%)$ \\
\hline Centrally acting antihypertensives & $32(58.2 \%)$ \\
\hline Other antihypertensives & $2(3.6 \%)$ \\
\hline Median number of antihypertensives & $4(3 ; 6)$ \\
\hline
\end{tabular}

Data are mean $(\mathrm{SD})$ when normally distributed and median $\left(5^{\text {th }}\right.$ and $95^{\text {th }}$ percentile range $)$ when they have non-normal distribution. Categorical variables are count (\%).

*Average of $2^{\text {nd }}$ and $3^{\text {rd }}$ office BP measurement.

${ }^{\dagger}$ Calculated as serum aldosterone (ng/L)/[10 x plasma renin activity (ng/mL/h)].

Per protocol, to make the trial results more easily transferable to non-study patients, all patients who presented at participating centres with resistant arterial hypertension and met the inclusion criteria were included in the trial ${ }^{20,21}$. In $24 \%$ of patients enrolled in the trial, a secondary cause of hypertension was found during subsequent evaluation after trial completion, with the most frequent cause being primary aldosteronism (61\%) $\left(\right.$ ref. $\left.^{21}\right)$.

The possible influence of secondary causes of hypertension on the trial results was regularly discussed during presentations of the ASPIRANT trial data at a number of medical conferences. The speakers often postulated that in patients with secondary hypertension, the effect of spironolactone would be less marked. However, this analysis showed the reverse. As primary aldosteronism is the most common cause of secondary hypertension, both in clinical practice and in this trial ${ }^{21,26}$, it is logical to expect an effective lowering of BP from spironolactone in this group of patients. Some degree of aldosterone excess often plays a role in patients with essential resistant 
Table 2. Change of patient characteristics after 8 weeks of treatment compared to baseline according to tertiles of systolic blood pressure at entry.

\begin{tabular}{|c|c|c|c|c|}
\hline Patient characteristics & $1^{\text {st }}$ Tertile* & $2^{\text {nd }}$ Tertile* & $3^{\text {rd }}$ Tertile* & $\boldsymbol{P}^{\dagger}$ \\
\hline Systolic blood pressure $(\mathrm{mmHg})$ & $<149$ & $149-159$ & $>159$ & \\
\hline Spironolactone group $(\mathrm{N})$ & 13 & 22 & 20 & \\
\hline \multicolumn{5}{|l|}{ Systolic BP } \\
\hline ABPM day-time systolic BP & $-6.0( \pm 9.1)$ & $-10.2( \pm 13.3)$ & $-10.4( \pm 14.0)$ & 0.512 \\
\hline ABPM night-time systolic BP ( $\mathrm{mmHg}$ ) & $-10.7( \pm 14.7)$ & $-14.3( \pm 20.1)$ & $-8.0( \pm 16.8)$ & 0.663 \\
\hline 24-h ABPM systolic BP (mmHg) & $-7.8( \pm 10.0)$ & $-13.2( \pm 11.8)$ & $-9.6( \pm 12.8)$ & 0.288 \\
\hline Office systolic BP (mmHg) & $-10.9( \pm 11.9)$ & $-15.4( \pm 14.3)$ & $-16.2( \pm 19.1)$ & 0.416 \\
\hline \multicolumn{5}{|l|}{ Diastolic BP } \\
\hline ABPM day-time diastolic BP ( $\mathrm{mmHg})$ & $-0.7( \pm 9.5)$ & $-5.8( \pm 7.3)$ & $-4.5( \pm 7.5)$ & 0.397 \\
\hline ABPM night-time diastolic $\mathrm{BP}(\mathrm{mmHg})$ & $-6.6( \pm 9.1)$ & $-6.3( \pm 9.9)$ & $-4.1( \pm 12.3)$ & 0.907 \\
\hline 24-h ABPM diastolic BP (mmHg) & $-2.2( \pm 7.6)$ & $-5.7( \pm 6.5)$ & $-3.8( \pm 7.0)$ & 0.456 \\
\hline Office diastolic BP $(\mathrm{mmHg})$ & $-5.3( \pm 8.8)$ & $-7.2( \pm 10.5)$ & $-6.8( \pm 9.4)$ & 0.706 \\
\hline \multicolumn{5}{|l|}{ Pulse pressure $^{\S}$} \\
\hline ABPM day-time pulse pressure $(\mathrm{mmHg})$ & $-5.3( \pm 5.4)$ & $-4.3( \pm 9.5)$ & $-5.8( \pm 9.2)$ & 0.987 \\
\hline ABPM night-time pulse pressure $(\mathrm{mmHg})$ & $-4.0( \pm 9.6)$ & $-8.0( \pm 14.3)$ & $-3.9( \pm 13.2)$ & 0.504 \\
\hline 24-h ABPM pulse pressure (mmHg) & $-5.6( \pm 5.0)$ & $-7.5( \pm 7.4)$ & $-5.9( \pm 8.3)$ & 0.488 \\
\hline Office pulse pressure $(\mathrm{mmHg})^{\ddagger}$ & $-5.6( \pm 10.1)$ & $-8.3( \pm 9.2)$ & $-9.4( \pm 13.9)$ & 0.378 \\
\hline
\end{tabular}

Data are mean (SD).

*Defined on the base of the whole dataset.

${ }^{\dagger}$ Statistical significance was tested by Kruskal Wallis test.

${ }^{\S}$ Calculated as systolic BP minus diastolic BP in all measured parameters.

Table 3. Change of patient characteristics after 8 weeks of treatment compared to baseline according to tertiles of diastolic blood pressure at entry.

\begin{tabular}{|c|c|c|c|c|}
\hline Patients characteristics & 1st Tertile* & 2nd Tertile* & 3rd Tertile* & $\boldsymbol{P}^{\dagger}$ \\
\hline Diastolic blood pressure (mmHg) & $<88$ & $88-97$ & $>97$ & \\
\hline Spironolactone group (N) & 16 & 18 & 21 & \\
\hline \multicolumn{5}{|l|}{ Systolic BP } \\
\hline ABPM day-time systolic BP & $-8.3( \pm 11.6)$ & $-14.2( \pm 11.5)$ & $-5.8( \pm 13.4)$ & 0.117 \\
\hline ABPM night-time systolic BP (mmHg) & $-12.1( \pm 14.8)$ & $-13.0( \pm 15.7)$ & $-8.8( \pm 21.4)$ & 0.540 \\
\hline 24-h ABPM systolic BP (mmHg) & $-10.2( \pm 11.2)$ & $-14.3( \pm 9.7)$ & $-7.8( \pm 13.4)$ & 0.203 \\
\hline Office systolic BP (mmHg) & $-13.4( \pm 11.6)$ & $-23.8( \pm 12.8)$ & $-7.7( \pm 17.0)$ & 0.010 \\
\hline \multicolumn{5}{|l|}{ Diastolic BP } \\
\hline ABPM day-time diastolic BP (mmHg) & $-3.0( \pm 6.3)$ & $-6.6( \pm 6.2)$ & $-3.0( \pm 10.2)$ & 0.286 \\
\hline ABPM night-time diastolic $\mathrm{BP}(\mathrm{mmHg})$ & $-2.9( \pm 11.6)$ & $-8.5( \pm 9.2)$ & $-5.1( \pm 10.5)$ & 0.307 \\
\hline 24-h ABPM diastolic BP (mmHg) & $-2.6( \pm 5.8)$ & $-6.6( \pm 5.2)$ & $-3.2( \pm 8.7)$ & 0.159 \\
\hline Office diastolic BP (mmHg) & $-1.5( \pm 7.9)$ & $-12.1( \pm 5.0)$ & $-5.8( \pm 11.5)$ & 0.003 \\
\hline \multicolumn{5}{|l|}{ Pulse pressure ${ }^{\S}$} \\
\hline ABPM day-time pulse pressure $(\mathrm{mmHg})$ & $-5.3( \pm 9.1)$ & $-7.6( \pm 8.9)$ & $-2.8( \pm 7.1)$ & 0.225 \\
\hline ABPM night-time pulse pressure $(\mathrm{mmHg})$ & $-9.2( \pm 7.8)$ & $-4.5( \pm 12.4)$ & $-3.7( \pm 15.9)$ & 0.298 \\
\hline 24-h ABPM pulse pressure (mmHg) & $-7.6( \pm 6.9)$ & $-7.7( \pm 7.5)$ & $-4.6( \pm 7.1)$ & 0.360 \\
\hline Office pulse pressure $(\mathrm{mmHg})^{\ddagger}$ & $-11.9( \pm 9.5)$ & $-11.8( \pm 10.0)$ & $-1.9( \pm 11.1)$ & 0.008 \\
\hline
\end{tabular}

Data are mean (SD).

* Defined on the base of the whole dataset.

${ }^{\dagger}$ Statistical significance was tested by Kruskal Wallis test.

${ }^{\S}$ Calculated as systolic BP minus diastolic BP in all measured parameters. 
Table 4. Change of patient characteristics after 8 weeks of spironolactone treatment compared to baseline according to the presence or absence of secondary hypertension.

\begin{tabular}{lccc}
\hline Patient characteristics & Secondary HT: no & Secondary HT: yes & $\boldsymbol{P}^{\dagger}$ \\
\hline Spironolactone group (N) & 42 & 13 \\
\hline Systolic BP & & $-8.8( \pm 13.1)$ & 0.905 \\
ABPM day-time systolic BP & $-9.4( \pm 12.6)$ & $-12.2( \pm 11.8)$ & 0.874 \\
ABPM night-time systolic BP (mmHg) & $-10.8( \pm 19.2)$ & $-10.7( \pm 11.3)$ & 0.898 \\
24-h ABPM systolic BP (mmHg) & $-10.6( \pm 12.0)$ & $-17.2( \pm 16.9)$ & 0.984 \\
Office systolic BP (mmHg) & $-13.9( \pm 15.3)$ & $-2.4( \pm 7.0)$ & 0.352 \\
Diastolic BP & & $-4.3( \pm 8.4)$ & 0.445 \\
ABPM day-time diastolic BP (mmHg) & $-4.7( \pm 8.3)$ & $-3.2( \pm 6.5)$ & 0.513 \\
ABPM night-time diastolic BP (mmHg) & $-6.0( \pm 11.1)$ & $-6.3( \pm 12.0)$ & 0.890 \\
24-h ABPM diastolic BP (mmHg) & $-4.5( \pm 7.2)$ & & \\
Office diastolic BP (mmHg) & & \\
Pulse pressure & $-6.7( \pm 8.9)$ & $-6.4( \pm 9.4)$ & $-8.0( \pm 6.6)$ \\
ABPM day-time pulse pressure $(\mathrm{mmHg})$ & $-4.7( \pm 8.2)$ & $-7.5( \pm 7.2)$ & 0.543 \\
ABPM night-time pulse pressure (mmHg) & $-4.8( \pm 14.2)$ & $-10.8( \pm 12.9)$ & 0.890 \\
24-h ABPM pulse pressure (mmHg) & $-6.1( \pm 7.3)$ & & 0.627 \\
Office pulse pressure (mmHg) & $-7.2( \pm 10.7)$ & & \\
\hline
\end{tabular}

Data are mean (SD). HT = hypertension.

† Statistical significance was tested by Mann-Whitney U test.

${ }^{\S}$ Calculated as systolic BP minus diastolic BP in all measured parameters.

hypertension, and thus, in those patients, the addition of aldosterone antagonists seems correct from the pathophysiological viewpoint.

Several previous trials suggested that blood pressure decrease with treatment is higher in patients with higher baseline systolic and diastolic BP. In a cohort of 46 patients with resistant hypertension and chronic stage 2 or 3 kidney disease reported by Khosla et al, patients with systolic $\mathrm{BP}$ values $\geq 160 \mathrm{mmHg}$ and $\mathrm{BMI} \geq 30 \mathrm{~kg} / \mathrm{m}^{2}$ at baseline were more likely to have $\mathrm{a} \geq 15 \mathrm{mmHg}$ reduction in systolic BP, compared to the index visit, with an odds ratio of $1.63(P=0.03)$ (ref. $\left.{ }^{14}\right)$.

A multiple regression analysis by Rodilla et al. of a prospective trial comparing spironolactone and doxazosin treatment in resistant hypertension, found the reduction in systolic BP after treatment to be independently associated with baseline systolic BP (=0.6, 95\% CI, 0.4-0.9; $P<0.001)$ and the reduction of diastolic BP independently associated with the baseline diastolic $\mathrm{BP}(\beta=0.5,95 \% \mathrm{CI}$, $0.3-0.7 ; P \leq 0.001)\left(\right.$ ref. $\left.^{27}\right)$. Patients with baseline systolic $\mathrm{BP}<165 \mathrm{mmHg}$ had a 2.56 times higher odds ratio of reaching good blood pressure control than patients with baseline systolic $\mathrm{BP} \geq 165 \mathrm{mmHg}(P=0.03)\left(\right.$ ref. $\left.^{27}\right)$.

Recent analysis by Janssen et al. showed that a change in BP with aldosterone antagonist treatment correlated significantly with baseline BP, urinary albumin-to-creatinine ratio, left ventricular hypertrophy and follow-up duration $^{28}$. In the multivariate analysis, only higher baseline BP and longer follow-up duration independently predicted $\mathrm{BP}$ response in the long term ${ }^{28}$.

In our analysis, the magnitude of BP reduction after spironolactone treatment did not differ significantly be- tween patients with lower and higher baseline systolic BP. A surprising finding is that the reduction of office systolic and diastolic BP was highest in the middle tertile of baseline diastolic BP between 88 and $97 \mathrm{mmHg}$, with a less than expected BP decrease in the highest tertile with baseline diastolic BP $>97 \mathrm{mmHg}$. Although patient compliance was assessed by the number of returned tablets ${ }^{21}$, we suggest that this discrepancy may be explained by a possibly poorer compliance with regard to the antihypertensive medications in patients with the highest baseline BP values.

Non-compliance with treatment in resistant hypertension may be more common than previously thought. In patients evaluated for secondary causes of hypertension in a tertiary hypertension centre, the total ratio of noncompliant patients was found to be higher than $32 \%$ when assessed by the measurement of serum values of antihypertensive drugs ${ }^{29}$. Our findings warrant further research, since the high baseline diastolic BP > $97 \mathrm{mmHg}$ despite treatment with multiple antihypertensive drugs could possibly identify patients with poorer treatment compliance.

A potential limitation of this analysis is the relatively small sample size. It is possible that recruitment of a substantially larger number of patients may have shown a more pronounced effect of spironolactone in certain subgroups.

\section{CONCLUSION}

Spironolactone treatment is effective to a similar extent in patients with and without a secondary cause of 
hypertension and regardless of the baseline systolic BP. Less effect of spironolactone was found in patients with highest baseline diastolic BP.

Further research is warranted to find whether the ontreatment office blood pressure values may be useful for identifying non-compliant patients.

\section{ACKNOWLEDGEMENT}

This work was supported by a restricted grant from the Czech Society for Hypertension. Richter Gedeon Ltd. (Czech Republic) provided the spironolactone for the preparation of the randomized medication and covered trial insurance.

\section{CONFLICT OF INTEREST STATEMENT}

Author's conflict of interest disclosure: The authors stated that there are no conflicts of interest regarding the publication of this article.

\section{REFERENCES}

1. Calhoun DA, Jones D, Textor S, Goff DC, Murphy TP, Toto RD, White A, Cushman WC, White W, Sica D, Ferdinand K, Giles TD, Falkner B, Carey RM; American Heart Association Professional Education Committee. Resistant hypertension: diagnosis, evaluation, and treatment: a scientific statement from the American Heart Association Professional Education Committee of the Council for High Blood Pressure Research. Circulation 2008;117:e510-26.

2. Cushman WC, Ford CE, Cutler JA, Margolis KL, Davis BR, Grimm RH, Black HR, Hamilton BP, Holland J, Nwachuku C, Papademetriou V, Probstfield J, Wright JT Jr, Alderman MH, Weiss RJ, Piller L, Bettencourt J, Walsh SM; ALLHAT Collaborative Research Group. Success and predictors of blood pressure control in diverse North American settings: the antihypertensive and lipid-lowering treatment to prevent heart attack trial (ALLHAT). J Clin Hypertens (Greenwich) 2002;4:393-404.

3. Black HR, Elliott WJ, Grandits G, Grambsch P, Lucente T, White WB, Neaton JD, Grimm RH Jr, Hansson L, Lacourciere Y, Muller J, Sleight P, Weber MA, Williams G, Wittes J, Zanchetti A, Anders RJ; CONVINCE Research Group. Principal results of the Controlled Onset Verapamil Investigation of Cardiovascular End Points (CONVINCE) trial. JAMA 2003;289:2073-82.

4. Persell SD. Prevalence of resistant hypertension in the United States, 2003-2008. Hypertension 2011;57(6):1076-80.

5. Hansson L, Zanchetti A, Carruthers SG, Dahlöf B, Elmfeldt D, Julius S, Ménard J, Rahn KH, Wedel H, Westerling S. Effects of intensive bloodpressure lowering and low-dose aspirin in patients with hypertension: principal results of the Hypertension Optimal Treatment (HOT) randomised trial. HOT Study Group. Lancet 1998;351:1755-1762.

6. Batterink J, Stabler SN, Tejani AM, Fowkes CT. Spironolactone for hypertension. Cochrane Database Syst Rev 2010;8:CD008169.

7. Ghose RP, Hall PM, Bravo EL. Medical management of aldosteroneproducing adenomas. Ann Intern Med 1999;131:105-8.

8. Lim PO, Jung RT, MacDonald TM. Raised aldosterone to renin ratio predicts antihypertensive efficacy of spironolactone: a prospective cohort follow-up study. Br J Clin Pharmacol 1999;48:756-60.

9. Ouzan J, Pérault C, Lincoff AM, Carré E, Mertes M. The role of spironolactone in the treatment of patients with refractory hypertension. Am J Hypertens 2002;15:333-9.

10. Nishizaka MK, Zaman MA, Calhoun DA. Efficacy of low-dose spironolactone in subjects with resistant hypertension. Am J Hypertens 2003; 16:925-30.
11. Sharabi Y, Adler E, Shamis A, Nussinovitch N, Markovitz A, Grossman E. Efficacy of add-on aldosterone receptor blocker in uncontrolled hypertension. Am J Hypertens 2006;19:750-5.

12. Lane DA, Shah S, Beevers DG. Low-dose spironolactone in the management of resistant hypertension: a surveillance study. J Hypertens 2007;25:891-4.

13. Chapman N, Dobson J, Wilson S, Dahlöf B, Sever PS, Wedel H, Poulter NR; Anglo-Scandinavian Cardiac Outcomes Trial Investigators. Effect of spironolactone on blood pressure in subjects with resistant hypertension. Hypertension 2007;49:839-45.

14. Khosla N, Kalaitzidis R, Bakris GL. Predictors of hyperkalemia risk following hypertension control with aldosterone blockade. Am J Nephrol 2009;30(5):418-24.

15. Ubaid-Girioli S, Adriana de Souza L, Yugar-Toledo JC, Martins LC, Ferreira-Melo S, Coelho OR, Sierra C, Coca A, Pimenta E, Moreno H. Aldosterone excess or escape: Treating resistant hypertension. J Clin Hypertens (Greenwich) 2009;11(5):245-52.

16. Alvarez-Alvarez B, Abad-Cardiel M, Fernandez-Cruz A, Martell-Claros N. Management of resistant arterial hypertension: role of spironolactone versus double blockade of the renin-angiotensin-aldosterone system. J Hypertens 2010;28(11):2329-35.

17. de Souza F, Muxfeldt E, Fiszman R, Salles G. Efficacy of spironolactone therapy in patients with true resistant hypertension. Hypertension 2010;55(1):147-52.

18. Engbaek M, Hjerrild M, Hallas J, Jacobsen IA. The effect of low-dose spironolactone on resistant hypertension. J Am Soc Hypertens 2010;4(6):290-4.

19. Abolghasmi R, Taziki O. Efficacy of low dose spironolactone in chronic kidney disease with resistant hypertension. Saudi J Kidney Dis Transpl 2011;22(1):75-8.

20. Václavík J, Kociánová E, Táborský M. Use of spironolactone in the treatment of resistant arterial hypertension. Cor Vasa 2011;53:343-7.

21. Václavík J, Sedlák R, Plachý M, Navrátil K, Plášek J, Jarkovský J, Václavík T, Husár R, Kociánová E, Táborský M. Addition of Spironolactone in Patients With Resistant Arterial Hypertension (ASPIRANT): A Randomized, Double-Blind, Placebo-Controlled Trial. Hypertension 2011;57(6):1069-75.

22. Vaclavik J, Sedlak R, Plachy M, Navratil K, Plasek J, Husar R, Kocianova E, Taborsky M. Addition of spironolactone in patients with resistant arterial hypertension (ASPIRANT) - study protocol. Biomed Pap Med Fac Univ Palacky Olomouc Czech Repub. 2011;155(2):143-8.

23. O'Brien E, Waeber B, Parati G, Staessen J, Myers MG, on behalf of the European Society of Hypertension Working Group on Blood Pressure Monitoring. Blood pressure measuring devices: recommendations of the European Society of Hypertension. Brit Med J 2001;322:531-6.

24. Association for the Advancement of Medical Instrumentation. American national standard. Electronic or automated sphygmomanometers. Arlington, VA:AAMI; 1993.

25. O'Brien E, Asmar R, Beilin L, Imai Y, Mancia G, Mengden T, Myers M, Padfield P, Palatini P, Parati G, Pickering T, Redon J, Staessen J, Stergiou G, Verdecchia P; European Society of Hypertension Working Group on Blood Pressure Monitoring. Practice guidelines of the European Society of Hypertension for clinic, ambulatory and self blood pressure measurement. J Hypertens 2005;23:697-701.

26. Omura M, Saito J, Yamaguchi K, Kakuta Y, Nishikawa T. Prospective study on the prevalence of secondary hypertension among hypertensive patients visiting a general outpatient clinic in Japan. Hypertens Res 2004;27(3):193-202.

27. Rodilla E, Costa JA, Pérez-Lahiguera F, Baldó E, González C, Pascual $J M$. Spironolactone and doxazosin treatment in patients with resistant hypertension. Rev Esp Cardiol 2009;62(2):158-66.

28. Jansen PM, Verdonk K, Imholz BP, Jan Danser AH, van den Meiracker $\mathrm{AH}$. Long-term use of aldosterone-receptor antagonists in uncontrolled hypertension: a retrospective analysis. Int J Hypertens 2011;2011:368140.

29. Chytil L, Strauch B, Cvačka J, Marešová V, Widimský J Jr, Holaj R, Slanař O. Determination of doxazosin and verapamil in human serum by fast LC-MS/MS: application to document non-compliance of patients. J Chromatogr B Analyt Technol Biomed Life Sci 2010;878(30):3167-73. 